\title{
Multilateral aid to the rescue? Sectoral fragmentation of bilateral development aid and the role of the World Bank
}

\author{
Martin C. Steinwand* \\ Bernhard Reinsberg ${ }^{\dagger}$
}

September 16, 2021

\begin{abstract}
Bilateral aid projects continue to proliferate in an uncoordinated fashion, leading to fragmented aid delivery. In this paper, we explore the role of the World Bank in promulgating best practices and enhancing sectoral coordination among bilateral donors. We concentrate on sectoral aid allocations and identify possible venues through which the World Bank can affect bilateral donor behavior and increase allocative efficiency, including as Lead Partner, Balancer, and by leading by example through Best Practices. Based on project-level data from 1998 to 2013, we find that bilateral donors and the World Bank allocate projects in a complementary fashion across most sectors, with the exception of the Finance and Trade sectors. Furthermore, World Bank and bilateral project numbers move together and there is some evidence that bilateral donors emulate World Bank behavior. There is very limited evidence that World Bank activities help to reduce bilateral aid fragmentation.
\end{abstract}

Keywords: World Bank; Donor Coordination; Bilateral Aid; Sectoral Aid.

\footnotetext{
*Corresponding Author. Department of Government, University of Essex, martin.steinwand@essex.ac.uk. ORCID: 0000-0002-4218-0164

†School of Social \& Political Sciences, University of Glasgow, bernhard.reinsberg@glasgow.ac.uk. ORCID: 0000-0001-7382-413X
} 


\section{Introduction $^{1}$}

Recent years have seen a continuing fragmentation of how bilateral donors deliver Official Development Aid (ODA). Despite much public debate since the 2005 Better Aid Agenda, there appears to be no detectable increase in coordination between donors, which could help to limit fragmentation (Nunnenkamp, Öhler and Thiele, 2013; Nunnenkamp, Sotirova and Thiele, 2015). In this article, we explore a policy venue with potentially large consequences for aid fragmentation that until now has received little attention in the literature. The World Bank frequently is the largest donor and development actor in individual sectors and countries. It is often overlooked that bilateral aid allocation decisions do not happen in a political and policy vacuum. Instead, donors governments make strategic decisions to what extent they are going to give up control of aid allocations by providing funding through World Bank and other multilateral channels (Milner, 2006). ${ }^{2}$ At the same time, the World Bank also acts as repository for policy knowledge and establishes best policy practices (The World Bank, 1998). This suggests that donor agencies should emulate World Bank practices to help reduce fragmentation. In this paper, we explore to what extent fragmentation of bilateral aid delivery is moderated or driven by World Bank activities. We focus in particular on fragmentation of bilateral aid allocations across sectors, and on the proliferation of individual projects within specific sectors. We argue that World Bank activities have the potential to reduce project proliferation if bilateral donors emulate World Bank best practices, but emulating World Bank allocation decisions also allows aid agencies an opportunity to increase visibility of their own activities.

One important driver of the policy debate on donor coordination is the strong increase, over the last 30 years, in the number of bilateral donors, the number of facilities through

\footnotetext{
${ }^{1}$ Replication data for this article can be found at https://doi.org/10.7910/DVN/X8PC4V. Online Supplemental Material can be found at https://drive.google.com/file/d/14bWsAmgv3-4Rnj2NNm_ 9C7i-02chh6TK/view?usp=sharing.

${ }^{2}$ This piece concentrates on classic multilateral aid, and does not look at earmarked funding. Future research should extend the arguments made here to include this increasingly salient mode of aid giving.
} 
which individual donors channel aid, and the decreasing size of individual projects (Kilby, 2011). Together, these trends have led to an explosion in the number of projects that are implemented each year in individual recipient countries and sectors. These trends continue unabated. Figure 1 shows both, the average number of projects per year and sector, and the average amount committed per project. Both indicators show a remarkable trend from 1990 to 2013 (the last year available in AidData's project data, Tierney et al., 2011; AidData, 2017). Average project numbers have increased from less than 2 to around 7, an increase of 250 percent, whereas individual projects have decreased in size from a peak of 25 million US dollars to around 5 million, representing a drop of 80 percent.

Figure 1: Project Size \& No. of Projects, All Sectors

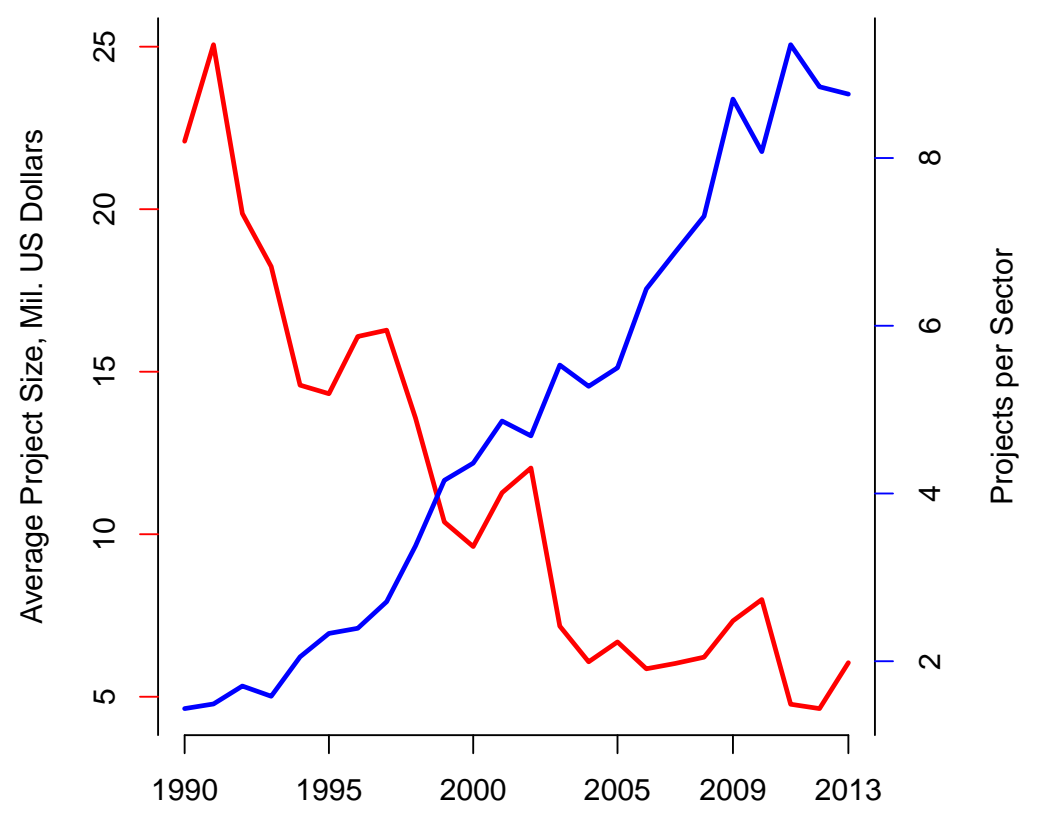

From an economic perspective, project proliferation in itself is not inherently bad or good. The development paradigm of the 1960s and 70s focused on capital spending and resulted frequently in a low number of large scale infrastructure projects. More often than not these turned out to be costly 'white elephants' that did not generate the promised boost to overall economic activity and productivity (e.g. Easterly, 2001). In 
contrast, smaller projects have the potential to better reflect local institutional realities (Ostrom, Schroeder and Wynne, 1993) and to enfranchise local stakeholders. At the same time, some projects might benefit from economies of scale, and implementing a large number of projects will invariably be associated with higher transaction costs. Thus there are potential economic drawbacks from project proliferation. While the theoretical perspective identifies these countervailing effects, there is important empirical evidence that suggests real negative consequences of proliferation for aid effectiveness. Kimura, Mori and Sawada (2012) find that greater donor fragmentation is associated with lower economic growth in the aggregate. ${ }^{3}$ Gehring et al. (2017) confirm this result, but show that problems arise only in countries with low quality bureaucratic institutions (which tend to be the poorest nations). However, they also disaggregate the data by sector to demonstrate that in education, fragmentation actually has a positive effect on educational outcomes. Hence, a sector perspective is crucial when analyzing project proliferation.

In addition to economic considerations, there are important political consequences of project proliferation as well. In an influential study, Knack and Rahman (2007) tie fragmented aid delivery to deteriorating donor bureaucratic quality, as an increasing number of projects places higher demands on local bureaucracies, and well-paying donor agencies poach talent from local governments. Fragmentation can also increase rent seeking, as recipients governments have greater opportunities for political capture when dealing with more bureaucratic contact points (for an example from Indonesia see Winters, 2012). On the donor side, bureaucratic incentives can play a role, as project proliferation increases the visibility of aid agencies (Kilby, 2011), a practice known as as 'flag planting'. This helps to legitimize the agencies' work in the eyes of policy principals such as cabinet level decision makers and donor publics, and potentially undermines best policy practices regarding aid effectiveness.

On balance, the takeaway for evaluating donor proliferation is an indeterminate outlook for economic results, but a clear potential for negative political side effects. The in-

\footnotetext{
${ }^{3}$ They don't look at project numbers or proliferation, but instead rely on a Herfindahl index of donor aid shares.
} 
ternational donor community recognized this in the Accra Agenda (OECD, 2008), which specifically pointed to "too many duplicating initiatives, especially at country and sector levels", and called for "improving the complementarity of donors' efforts ... including through improved allocation of resources within sectors, within countries, and across countries." (OECD, 2008:p. 17). There is a number of studies that have explored whether aid allocation patterns have changed in the wake of this policy pronouncement (Nunnenkamp, Öhler and Thiele, 2013; Nunnenkamp, Sotirova and Thiele, 2015). Overall, they do not find changes in bilateral donor behavior. While this is an important insight, missing from the academic debate is a focus on which actors can be effective in promoting greater coordination and the mechanisms through which changes in donor behavior can be brought about.

This paper starts from the premise that the World Bank is a primary candidate to fill this policy leadership role (Heldt and Schmidtke, 2019). It looks at interactions between World Bank engagement (specifically projects by the International Bank for Reconstruction and Development, the International Development Association, the Carbon Finance Unit, and the International Finance Corporation) and bilateral aid allocation decisions. We focus on the World Bank because in many sectors it plays an outsize role. For example, in the energy sector World Bank projects account for 10 percent of all aid flows, making the World Bank easily the largest single donor. Part of why size matters is the widely recognized ability of the World Bank to define best practices for aid policies (for critical assessments see Rodrik, 2008; Courtright, 2004). Importantly, this is not just a matter of passive influence. The bank sees itself in the role of policy setter (for an examplary articulation of this see Fritz, Kaiser and Levy, 2009). ${ }^{4}$

In this paper, we focus on project proliferation and identify two possible ways in which this influence could play out. First, if the World Bank acts as policy setter, we expect it to promote sectoral aid specialization in the sense of the Accra Agenda. Hence, World Bank

\footnotetext{
${ }^{4}$ The intensity of this sense of mission has varied over time. One high point of the approach occurred with James Wolfensohn's declaration of the 'Knowledge Bank' in 1996 and the subsequent introduction of the Comprehensive Development Framework (Weaver, 2008:150).
} 
engagement in one sector should serve as signal to bilateral donors to concentrate their efforts on different sectors. Even though previous research was not able to find evidence of bilateral coordination across sectors in the aggregate, the World Bank still might make a difference in nudging bilateral actors in this direction. Second, the World Bank influences bilateral donors through promulgating of best practices. If the Bank acts as policy leader for reduced project proliferation, bilateral donors should emulate the Bank's behavior and reduce project proliferation in specific sectors in which the Bank leads by example.

However, there are important arguments for why World Bank policy leadership might fail. Donors appreciate the World Bank's ability to impose policy conditionality on recipient governments, and therefore might follow the World Bank into specific sectors (Annen and Knack, 2018). This has the potential to undermine efforts at promoting cross-sector specialization. Likewise, donor bureaucracies might find it advantageous to locate projects in the same sectors as the World Bank and other bilateral donors, to increase their visibility, especially among policy principals (Eichenauer and Reinsberg, 2017). The World Bank itself is also not immune to outside influences. The severity of its loan conditions tends to align with how close a program country is politically to the US (Clark and Dolan, 2021), enforcement of conditions is less stringent if American or Japanese headquartered multinational corporations are involved in project delivery (Malik and Stone, 2018), and the Bank is more likely to engage in infrastructure intense sectors in response to Chinese development financing (Zeitz, 2021). We don't deny the importance of these influences, but highlight the relevance of the World Bank as policy setter, especially with regard to sectoral aid choices by western providers of Official Development Aid. In the theory section, we develop testable expectations for the policy leadership proposition and countervailing arguments, both with respect to sectoral aid allocation patterns and for the determinants of bilateral project counts.

The scope of this paper consciously excludes World Bank-managed trust funds. Trust funds constitute a hybrid between bilateral and multilateral aid, where bilateral donors draw on the bank's expertise but ultimately retain the ability to earmark aid for specific 
purposes or to experiment with new implementation facilities (Reinsberg, Michaelowa and Knack, 2017). While trust funds play an increasingly prominent role in bilateral aid activity (Eichenauer and Reinsberg, 2017), we are interested to what extent the World Bank itself reacts to aid proliferation and how the World Bank's own funding facilities affect bilateral project proliferation. The use of trust funds may well be affected by these interactions, forming a separate part of the puzzle worth exploring in future research.

This paper makes several contributions. Multilateral institutions have an important role to play in providing public goods and underwriting the international order (Kindleberger 1973; but see e.g. Snidal 1985). As the rise of new donors such as China puts pressure on existing policy practices (Humphrey and Michaelowa, 2019; Vadlamannati et al., 2019), and with evidence of bilateral donors failing to achieve coordination that reduces aid fragmentation and herding effects (Mascarenhas and Sandler, 2006; Davies and Klasen, 2019), ${ }^{5}$ this paper highlights the potential leadership role of the World Bank in shaping the foreign aid regime.

By focusing on donor coordination as a stated World Bank policy goal, the paper also speaks to the role of bureaucratic expertise in determining policy actions by international institutions (Bauer and Ege, 2016; Johnson and Urpelainen, 2014). This is a reversal of the usual principal-agent relationship where international organizations act according to the preferences of powerful member states (Stone, 2011; Schneider and Tobin, 2013).

Our research contributes to the debate on aid fragmentation by taking a sector perspective (Kilby, 2011; Nunnenkamp, Sotirova and Thiele, 2015). The results show that the relationship between World Bank and bilateral aid flows and project numbers vary widely by sector. Aggregate analysis cannot generate these granular insights. The paper is to our knowledge also the first to take serious the interdependence of donor sector allocation decisions and the resulting compositional nature of the data, using Dirichlet regressions (Hijazi and Jernigan, 2009) to correct for possible simultaneity bias.

\footnotetext{
${ }^{5}$ But see (Steinwand, 2015) for instances of collusion that shifts rents towards donors.
} 


\section{Theory}

The key question addressed in this paper is how the World Bank as multilateral institution influences how bilateral donors allocate aid within and across specific sectors. We argue that the Bank plays an important role in promoting best policies, and therefore should be well positioned to lead by example in reducing project proliferation in specific sectors. The theoretical rationale for this expectation is based on functionalist accounts as well as principal-agent approaches to multilateral aid.

From a functionalist perspective, multilateral financial institutions possess advantages that can provide valuable services to donor governments. Their professional staff are repositories of expertise, they collect financial information and compliance data about recipient countries, and they provide this information in turn to the public. This benefits donor governments because this type of information is costly to gather. There is also potential for biased information because recipient governments may benefit from hiding problems, while private economic actors have no incentive to share information with competitors. In this environment, the professionalization and institutional self-interest of multilateral financial institutions ensures unbiased information of high quality (Rodrik, 1995).

Multilateral institutions are also perceived to be relatively politically neutral by domestic audiences in both recipient and donor countries. This makes it easier for them to attach policy conditionality to aid programs (Rodrik, 1995). Donor governments benefit in turn from policy compliance for their own bilateral aid projects (Annen and Knack, 2018). A second benefit to donors is the increased legitimacy of aid programs more broadly in the eyes of a sceptical public, who sees support for multilateral institutions as ensuring political neutral and effective aid programming (Milner, 2006).

Principal-agent problems have the potential to undermine the World Bank's role as a promoter of best practices. The Bank is ultimately responsible to its shareholders, and donor governments as collective principal might pursue goals that conflict with gath- 
ering information and promulgating best policies. For example, a number of studies have identified economic self-interest as a major obstacle for coordination of bilateral aid flows (Fuchs, Nunnenkamp and Öhler, 2015; Steinwand, 2015). Donors as shareholders therefore might seek to constrain the Bank's role as policy setter.

Conversely, from the shareholders' perspective, the ability to influence World Bank practices is reduced when they hold conflicting policy preferences (this is the case when donors treat aid flows as competition for private advantages). In this situation, the collective principal will not be able to constrain actions of the agent (an example from joint EU aid programming comes from Schneider and Tobin, 2013). Fortunately, this lack of constraint might actually enhance the World Bank's role as information provider and policy setter. Rodrik (1995) emphasizes that to be able to act as politically neutral provider of information about recipient countries, multilateral donors actually require a degree of autonomy from their principals. He furthermore argues that actors like the World Bank have money at risk from loan based parts of their programs, and therefore have incentives that align them with shareholder interests. Arguably, the Bank's politically neutral outlook is reinforced by its organizational culture and its staff's academic background, which emphasizes economic over political analysis (Yanguas and Hulme, 2015).

This discussion suggests that the World Bank is in a strong position to formulate and promulgate best policies regarding aid project proliferation and the risk of duplication. In fact, the Bank has made this a hallmark of its own efforts in increasing aid efficiency. For example, a document of the World Bank's Operation Evaluation Department from 2000 highlights that the Bank has been promoting increased aid coordination since the 1950s (sic!) through the policy forums known as Consultative Groups. Not surprisingly, the Bank's key strategic vehicle for aid policy at the time, the Comprehensive Development Framework (CDF), is cast as key ingredient for coordination:

"Because aid coordination has increasingly involved a multitude of actors, it is closely linked with the notion of partnership, promoted by the Comprehensive Develoment Framework. ... [T] he CDF brings together all actors in 
the development process - government, multilateral and bilateral aid agencies, the private sector, nongovernmental organizations ..., and civil society." (World Bank Operations Evaluation Department, 2000:p. 1)

The prominence with which the Paris Agenda and the ensuing aid efficiency agenda treated donor proliferation and the urgent calls for increased coordination (e.g. Easterly, 2007) further increased the emphasis that the World Bank put on coordination. The Bank's 2005 Global Monitoring Report criticizes that aid delivery is fragmented, despite bilateral donors heavily focusing on a small number of countries. The report notes that "although donors have their favorite countries, they like to be present in many countries in the region." (The World Bank, 2005:p. 172).

Aid coordination continues to play an important role in the Bank's policy outlook today. The directive establishing the Bank's current development strategy (the Country Partnership Framework, CPF) specifies that the "[World Bank Group] collaborates and coordinates with development partners to leverage resources and seek greater coherence across institutions and alignment with the country's development priorities." (The World Bank, 2014) What observable implications should effective World Bank leadership in promoting donor coordination have? We focus on two aspects that the literature has identified as areas that would benefit from policy leadership and which have featured in the Bank's own analysis. The first are increased specialization of donors on individual sectors, and the second are a reduction in the number of projects per sector.

The notion that aid fragmentation can be combated by increased sectoral specialization rests on the observation that in some countries individual sectors receive substantively greater aid inflows, and experience a proliferation of projects by many different donors, while other sectors receive comparatively little aid. Specialization refers to a situation in which individual donors focus their efforts on just one or a few sectors, with little overlap between the sectors chosen by different donors. The World Bank recognizes sectoral specialization as a policy tool for fighting fragmentation. For example, a policy paper from the IDA's Operations Policy and Country Services describes the Bank's 
involvement in "division of labor exercises" as

"processes through which donors coordinate in limiting the number of sectors in which each is active. The goal is to reduce the transaction costs of intrasector coordination for the country government, ensuring a better allocation of resources across sectors and improving overall aid effectiveness." (International Development Association, 2007:p. 27)

Interviews with current World Bank staff reflect an awareness of this policy leader role in aid allocations across sectors. A senior economist in the Bank's Macroeconomics, Trade \& Investment Global Practice unit suggests that "one of the World Bank's comparative advantages is its convening power, bringing the donor community around the table for policy dialogue and aid coordination." With regard to sectoral allocations, he emphasizes that the Bank can attract cooperation from bilateral donors who "lack the technical expertise, knowledge and access to policymakers", and therefore rely on the Bank's "wide and often deep sectoral expertise". Likewise, he reports that a sectoral division of labor can "[happen] as a result of aid coordination", pointing as example to different sector focuses chosen by the World Bank and the Asian Development Bank. ${ }^{6}$

Despite such conscious efforts, aggregate aid allocation patterns provide little evidence that donors have changed their behavior (Nunnenkamp, Öhler and Thiele, 2013; Nunnenkamp, Sotirova and Thiele, 2015). However, this apparent lack of aggregate change does not mean that World Bank actions have no effect. It is possible that fragmentation would be even more pronounced without the Bank's leadership, and that other forces counteract what would otherwise be a policy success.

To look for evidence that World Bank actions are able to nudge donors towards greater sector specialization, we concentrate on substitution patterns of World Bank and bilateral aid allocations across sectors. To this end we leverage the fact that World Bank has the financial clout to act as "lead ...p partner" (International Development Association,

\footnotetext{
${ }^{6}$ Email correspondence, April 2021.
} 
2007:p. 27) in any specific sector, i.e. substitute its own aid payment to replace several bilateral donors. We argue that policy leadership in donor coordination can take two forms. First, as the World Bank takes a lead partner role and increases its aid allocations to a specific sector in a given country, bilateral donors in turn should decrease their own engagement in this sector (the Lead Partner Effect). Alternatively, the World Bank also has the capacity to balance out unequal aid allocations across sectors by shifting some of its aid to previously underaided, or "orphan" sectors (International Development Association, 2007:p. 17) - the Balancer Effect.

Both predictions suggest that there should be an observable relationship between bilateral and World Bank sector allocations within a country. To operationalize this, we start from the observation that both the Bank's budget for a specific recipient country and the amount of bilateral aid allocated to this country is relatively fixed in the short term. In contrast, the precise sector allocation within a given country budget is more flexible. It therefore makes sense to study the relationship between World Bank and bilateral sector specialization in terms of the relative aid shares directed to different sectors. As a result of the Lead Partner Effect, increases in World Bank aid shares dedicated to a specific sector should be met with a reallocation of bilateral flows to other sectors. Alternatively, under the Balancer Effect, as bilateral donors concentrate their aid allocations in an individual sector (thereby creating a "darling" sector), the World Bank should shift its allocations out of this and into different sectors. We summarize these predictions in the following hypotheses.

Hypothesis 1a - World Bank as Lead Partner: An increasing share of World Bank aid allocations in a specific sector is associated with a reduction of the bilateral aid share in this sector.

Hypothesis $1 b$ - World Bank as Balancer: An increasing share of bilateral aid allocations in a specific sector is associated with a reduction of the World Bank aid share in this sector. 
The two hypotheses are not competing in the sense that both causal mechanisms can operate at the same time. Below we present a causal identification strategy for Hypothesis 1a that relies on exogenous variation in the World Bank's overall aid portfolio and global sector allocation patterns. Though we lack good instruments for hypothesis 1b, regression can establish the existence of a substitution relationship (even if falling short of establishing causal direction). This in itself is important for understanding the relationship between World Bank and bilateral aid activity.

The case for World Bank policy leadership is not uncontroversial. Annen and Knack (2018) argue that bilateral donors benefit from the World Bank's focus on policy and poverty selectivity and the Bank's ability to impose strong conditionality with regard to these indicators on recipient governments. Treating World Bank conditionality as a public good that helps to enhance the effectiveness of their aid contributions, bilateral donors therefore tend to engage in the same sectors as the World Bank. This argument directly runs counter to the Lead Partner and Balancer logic. Instead of substituting multilateral for bilateral aid dollars (as Lead Partner), or the reverse (as Balancer), a strong, reinforcing relationship between sectoral aid flows from bilateral and multilateral sources suggests the existence of complementarities.

Additional potential sources of complementarities are bureaucratic incentives and donor competition. Bilateral aid allocation decisions are made by aid agency bureaucrats who need to justify their activities to political principals. Kilby (2011) argues that proliferating aid projects across sectors and emulating World Bank aid strategies helps to increase the visibility of aid agency activities, an effect labeled 'flag planting'. This mechanism can be particularly powerful in the presence of positive feedback effects, where political visibility increases as the number of donors who pile into the same sector grows. Similar complementarities arise in sectors where bilateral donors compete for political influence, for example if bilateral aid is used to promote donor exports (Fuchs, Nunnenkamp and Öhler, 2015; Steinwand, 2015). To the extent that World Bank engagement reduces the influence of bilateral donors, these might react with increased aid allocations. 
The observable implications of the mechanisms that induce complementarities in World Bank and bilateral sectoral aid allocations are the reverse from hypotheses 1a \& b:

Hypothesis 2 - Complementarity: An increasing (decreasing) share of World Bank aid allocations in a specific sector is associated with an increase (reduction) of the bilateral aid share allocated to this sector.

The second area in which the World Bank has the potential to provide policy leadership is the reduction of the number of aid projects per sector. The Bank has identified "too many small projects" as a cause of high transaction costs for recipient governments and as a source of potentially forgone economies of scale (The World Bank, 2005:p. 172). A direct way in which the bank can promote fewer and larger projects is by leading by example. We focus on two observable implications of this. First, when comparing specific sectors across countries with and without World Bank engagement, those without the benefit of the Bank's policy leadership should have systematically a higher number of bilateral aid projects. Second, capturing the learning effect over time, once the Bank starts engaging in a specific sector, the number of bilateral projects should start declining. This leads to the next two hypotheses.

Hypothesis $3 a$ - Learning from Best Practices, Outcomes: Across countries, identical sectors should have fewer bilateral projects in the presence of World Bank projects.

Hypothesis $3 b$ - Learning from Best Practices, Mechanism: In sectors that previously received no World Bank aid, entry of the World Bank should be associated with a declining number of bilateral aid projects.

The possibility of sectoral complementarities suggests that the Learning from the World Bank mechanism won’t always operate. Going back to the policy conditionality argument advanced by Annen and Knack (2018), donors are at liberty to proliferate 
projects in sectors in which the World Bank is active, without incentives to constrain the numbers of implemented projects. Similarly, if aid agency bureaucrats seek to increase donor visibility, World Bank engagement does not provide an incentive to reduce the number of projects. On the contrary, in the short-term, the best strategy that aid agencies have to plant their flag in sectors into which the World Bank enters for the first time is to quickly increase the number of projects in the sector, by shifting resources from other sectors. This does not require going through the relatively slow and politically uncertain process of increasing aggregate allocations to a country. The observable implication of sectoral complementarities in aid provision run counter to hypotheses $3 \mathrm{a} \& \mathrm{~b}$ :

Hypothesis 4: Across countries and over time, the presence of World Bank projects should be associated with a larger number of bilateral projects.

We discuss how to operationalize and test the hypotheses in the next section.

\section{Empirical Analysis}

The first part of the empirical analysis examines sectoral patterns of World Bank and bilateral aid allocations. The second part focuses on the influence of World Bank engagement on the number of bilateral aid projects.

The empirical analysis builds on project level aid data as reported in the AidData dataset (Tierney et al., 2011; AidData, 2017). ${ }^{7}$ Starting with sector codings based on the OECD's Creditor Reporting System, we aggregate the codes to correspond to top level categories. For example, all entries under subheadings such as 'Basic Health', 'Health, general', etc. are labeled as 'Health'. After removing sectors that account for money spent on donor expenses, pure accounting entities, and those in which the World Bank does not engage for statutory reasons, there remain 24 sectors in the analysis (a full list can be found in Online Supplementary Appendix A). ${ }^{8}$ The data cover the years 1998-2013

\footnotetext{
${ }^{7}$ All aid allocations are based on aid commitments, expressed in constant 2011 US Dollars.

${ }^{8}$ Examples of excluded sectors are 'action relating to debt', 'administrative costs of donors', and 'refugees in donor countries'.
} 
for 47 OECD donor countries and 189 recipients. $^{9}$

\subsection{Sectoral Specialization}

We begin with the first set of causal mechanisms through which the World Bank can influence sector level proliferation of bilateral aid. Both the Lead Partner and Balancer arguments stipulate that World Bank allocations act as substitute for bilateral aid across sectors. While we discuss differences in temporal ordering below, over time both mechanisms should lead to a sorting of World Bank and bilateral aid allocations into different sectors. Figure 2 provides a first glimpse if such specialization takes place. The graphs show all sectors ordered according to how much aid they receive from the World Bank, separately for the periods prior and after the Paris Declaration. Solid dots represent World Bank aid shares, whereas the diamonds show the share of bilateral aid going to each sector. If the World Bank and bilateral donors specialized on different sectors, we should expect bilateral allocations to follow a systematically different (and maybe even inverse) sectoral ordering than World Bank aid. This is not the case. While there are individual instances of strong divergence (e.g. in the Banking sector pre-2005, and in Emergency Response after 2005), bilateral aid shares closely track World Bank aid allocations. There is also no visible increase in sectoral specialization after the 2005 Paris Declaration.

This lack of a clear pattern of specialization is not unexpected. It is in line with the inability of existing studies to identify patterns of sectoral specialization in aggregate data. ${ }^{10}$ We have argued above that the World Bank still may have the ability to influence

\footnotetext{
${ }^{9}$ AidData also lists infrastructure projects in rich industrialized countries that received multilateral or even outside bilateral financing. For example, water projects in the US border region with Mexico received support from the North American Development Bank. There are no principled reasons to remove these observations from the analysis. However, the number of cases affected is minuscule and dropping instances of OECD donors receiving aid does not noticeably alter any results.

${ }^{10}$ Another possibility is that the World Bank and bilateral donors specialize into different sectors within countries, but alternate their sectoral focus from country to country. Such behavior would lead to no clear sectoral sorting in the aggregate. However, under this scenario the aggregate shares of aid going to different sectors should tend to grow more equal in size, yet there is no evidence of greater equalization and a suppressed range of sector shares in the post-Paris period.
} 


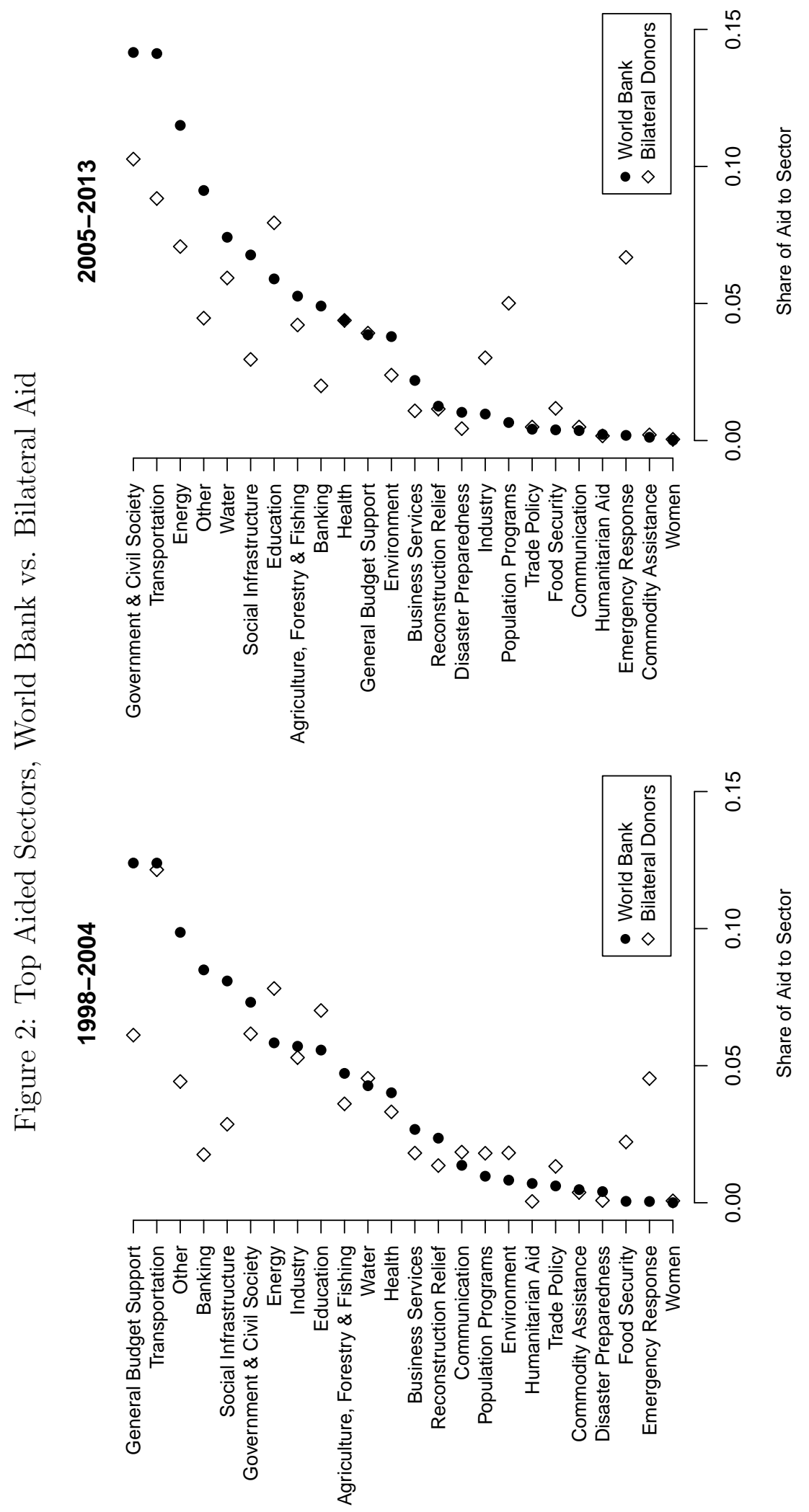


aid inter-sectoral allocation patterns at the margin. To get at this, we revisit the temporal ordering implied in hypotheses 1a \& b, and turn to multivariate analysis.

In terms of temporal ordering, under the Lead Partner mechanism, the World Bank moves into a sector, with bilateral aid subsequently leaving this sector. When acting as Balancer, the World Bank reacts to bilateral increases in a given sector by reallocating aid to other sectors. We describe in detail below how we incorporate this temporal ordering into the statistical analysis. This setup can establish the temporal sequence of co-variation, and more importantly, its direction. We already noted that the Lead Partner and Balancer hypotheses are not competing in nature, and our research design is capable of establishing evidence of the hypotheses' joint operation. To see why, consider how a causal interpretation of temporal co-variation is most likely to go wrong. For example, it is possible that the World Bank increases allocations to a particular sector in anticipation of a projected reduction in bilateral engagement. While a causal interpretation of this would incorrectly lend support to the Lead Partner hypothesis, the causal mechanism actually at work is that of the Balancer hypothesis. Likewise, if bilateral donors increase their engagement in a sector in anticipation of projected reductions in World Bank aid, this would incorrectly lend support to the Balancer hypothesis. However, the actual substitution relationship in this case is the one articulated by the Lead Partner hypothesis. Therefore, even though relying on temporal ordering does not allow for sharp causal distinctions between hypotheses $1 \mathrm{a} \& \mathrm{~b}$, it is capable of reliably identifying a substitution relationship that jointly supports the hypotheses.

In addition, for the Lead Partner mechanism we seek to establish causality by exploiting the fact that annual total volumes of World Bank giving vary with exogenous factors such as IDA replenishment, financial reflows to other World Bank facilities, and refinancing conditions. Employing a shift-share type instrumentation strategy (Bartik, 1991), we generate an instrument for the key independent variable, the share of World Bank aid going to a specific sector (per year and recipient country). The instrument is obtained by regressing this variable on the three-way interaction between the World 
Bank's general allocation pattern to this sector across all recipient countries, the exogenous variable driving aggregate World Bank giving, and the amount of aid allocated to the recipient country in this year. ${ }^{11}$ The intuition is that the World Bank has preferences for specific sectors that are independent of the situation in any individual recipient country and that the share of aid going to these sectors in turn depends on how much aid the Bank can provide in a given year. The interaction captures the part of the allocations to a given sector (per recipient country and year) that is driven by this exogenous World Bank preference. Estimation is done via a two-step procedure, accounting for estimation uncertainty via a non-parametric bootstrap procedure (Efron and Tibshirani, 1986). Note that the lack of good instruments for bilateral aid sector decisions prevents us from employing a similar strategy for the Balancer hypothesis (1b).

The size of sectoral aid shares is compositional in nature. That is, sector shares are constrained to lie between 0 and 1 and have to add up to 1 within a country in a given year. Existing studies typically work around these constraints by focusing not on sector shares, but on total aid amounts per sector. This risks introducing unmodeled correlation between errors, and therefore simultaneity bias, as the decision how to divide aid between sectors typically occurs within a fixed country-specific budget. To improve on this situation, we use Dirichlet regressions (Hijazi and Jernigan, 2009), which explicitly respect the sectoral composition of aid flows. ${ }^{12}$ Concentrating on sector shares has additional substantive advantages. The approach treats overall commitments to a country as fixed. Since we are interested in relatively short-term reactions to changes in donor behavior, this realistically mirrors donor practices. Aid agencies find it easier to respond to strategic changes by moving money from one sector to another, instead of going through cumbersome and slow legislative processes to increase total aid commitments to a country. The focus on sector shares therefore directly captures trade-offs that agencies need to make when adjusting aid allocations. A second advantage of sector shares is that this

\footnotetext{
${ }^{11}$ See online Appendix A for a detailed description.

${ }^{12}$ Note that another commonly used approach that accommodates shares, fractional logit, incorrectly assumes independence of observations across sectors, which is manifestly not the case with compositional data.
} 
approach does not require any further standardization (e.g. for recipient needs or size) when making comparisons across countries.

The Dirichlet model takes $C$ dependent variables $y_{c} \in[0,1]$, each of which captures the share of aid going to different sectors $c$. Shares across all sectors must add up to 1 , $\sum_{c=1}^{C} y_{c}=1$. The dependent variables $y_{c}$ follow a joint Dirichlet distribution according to

$$
\mathcal{D}(\boldsymbol{y} \mid \boldsymbol{\alpha})=\frac{1}{B(\boldsymbol{\alpha})} \prod_{c=1}^{C} y_{c}^{\left(\alpha_{c}-1\right)},
$$

where $B(\cdot)$ is the multinomial beta function. The parameters $\alpha_{c}$ are reparameterized to take predictors and covariates using a log-link function $\log \left(\alpha_{c}\right)=\boldsymbol{X}^{[c]} \boldsymbol{\beta}^{[c]}$ (Hijazi and Jernigan, 2009; Maier, 2014). Estimation is via maximum likelihood.

For the initial test of the Lead Partner and Balancer hypotheses, two separate versions of the model are estimated. For the Lead Partner model, the dependent variable $y_{t, i, c}$ is the share of bilateral aid (aggregated across all donors) going to sector $c$ in country $i$ during year $t$. The key independent variable is the share of World Bank aid $x_{t-1, i, c}$ going into the same sector. To ensure the correct temporal ordering of events, this variable is lagged by one year (as are all other independent variables). In addition, to account for idiosyncratic year-to-year volatility in aid commitments, we take a three year moving average of the variable, going back two additional years (the full specification can be found in online Supplementary Appendix A). Results are not sensitive to this particular specification choice. ${ }^{13}$ For the Balancer hypothesis, dependent and independent variables are reversed, with World Bank sector aid share as dependent and bilateral sector aid share as key independent variables.

In the Online Supplementary Appendix B, we present results with additional sectorspecific control variables. The rationale for doing so is to mitigate Galton's problem the challenge of untangling the effect of extraneous factors on aid shares from the effect of donor coordination. For example, for the education sector, we control for the pupil-

\footnotetext{
${ }^{13}$ When including the simple lagged version of the variable, the results persist, but effect sizes are somewhat smaller and estimated with less precision. Results are also robust to including up to 4 years in the moving average.
} 
teacher ratio and years of education, which jointly capture development needs to which donors might be expected to respond. To take food security as another example, we would want to control for the level of food prices, food price volatility, and the prevalence of undernourishment. Reassuringly, our coefficient estimates in the baseline model are not qualitatively affected when adding sector-specific control variables. This is especially true for our test of the lead partner hypothesis, while the results are less robust against inclusion of control variables for the balancer hypothesis. We refer readers to the Online Supplementary Appendix for full results and related discussion.

The output of a Dirichlet regression is difficult to interpret directly. Therefore, figure 3 provides an overview of the results, using marginal effects. ${ }^{14}$ The shown model includes common control variables, but no sector-specific controls. ${ }^{15}$ The left panel shows the specification testing the Lead Partner hypothesis, with bilateral sector aid shares as dependent variable, and the right panel the Balancer hypothesis, with World Bank sector aid shares as dependent variable. The dots represent marginal effects and the whiskers 95 percent confidence intervals. Recall that the key independent variable is a 3 -year moving average of World Bank (bilateral) sector shares, lagged by 1 year. To interpret the graphs, take for example the effect of World Bank allocations (averaged over years $t_{-3}$ to $t_{-1}$ ) to Food Security on bilateral aid allocations to this sector (in year $t_{0}$ ), third from the top in the left panel. The dot indicates that each increment of the World Bank's share of aid going to this sector is associated with an average increase in the share of bilateral aid by 4.7 percent.

The results strongly refute both the Lead Partner and Balancer hypotheses. The only sector for which we can observe a statistically significant substitution relationship is Humanitarian Aid, but effect sizes are vanishingly small (0.43 percent per increment) and the effect is only statistically significant in the left panel.

Instead, we have strong evidence for complementary behavior (hypothesis 2) across

\footnotetext{
${ }^{14}$ Full results are in Online Supplementary Appendix B.

${ }^{15}$ Standard errors are clustered on recipient country. Confidence bands were obtained through parametric resampling.
} 


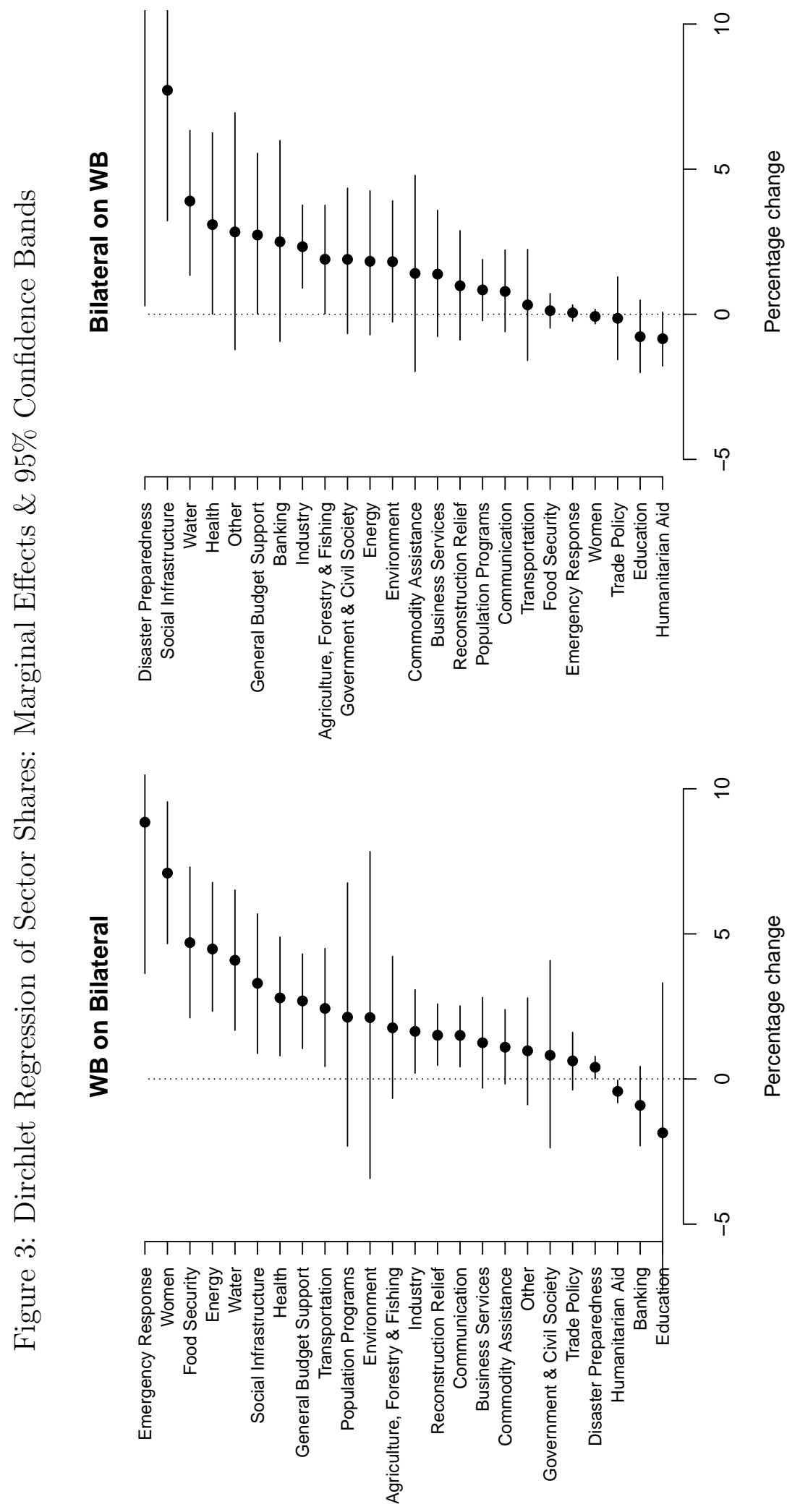


many sectors. Starting with the left panel, bilateral sector shares move in line with World Bank allocations across 13 of the 24 sectors). When adding additional sector specific controls, the positive relationship holds for 8 sectors, despite a much smaller $n$ (see Online Supplementary Appendix B). Effect sizes vary from 8.9 percent in the Emergency Response sector to 0.4 percent in Disaster Preparedness, with a median effect size of 2.8 percent (Health).

The evidence is less robust for the World Bank changing sector allocations in response to bilateral aid (right panel). The World Bank increases sector shares in line with bilateral allocations in 7 sectors. With the exception of Agriculture, in all of these sectors there exists a mutually responsive relationship. That is, bilateral and World Banks sector allocations respond to each other in both directions. Effect sizes are comparable to the left panel, ranging from 11 percent (Disaster Preparedness) to 1.9 percent (Agriculture), with a median effect size of 3.1 percent (Health).

Figure 4: Instrumented Dirichlet Regression of Sector Shares: Marginal Effects \& Bootstrapped 95\% Confidence Bands

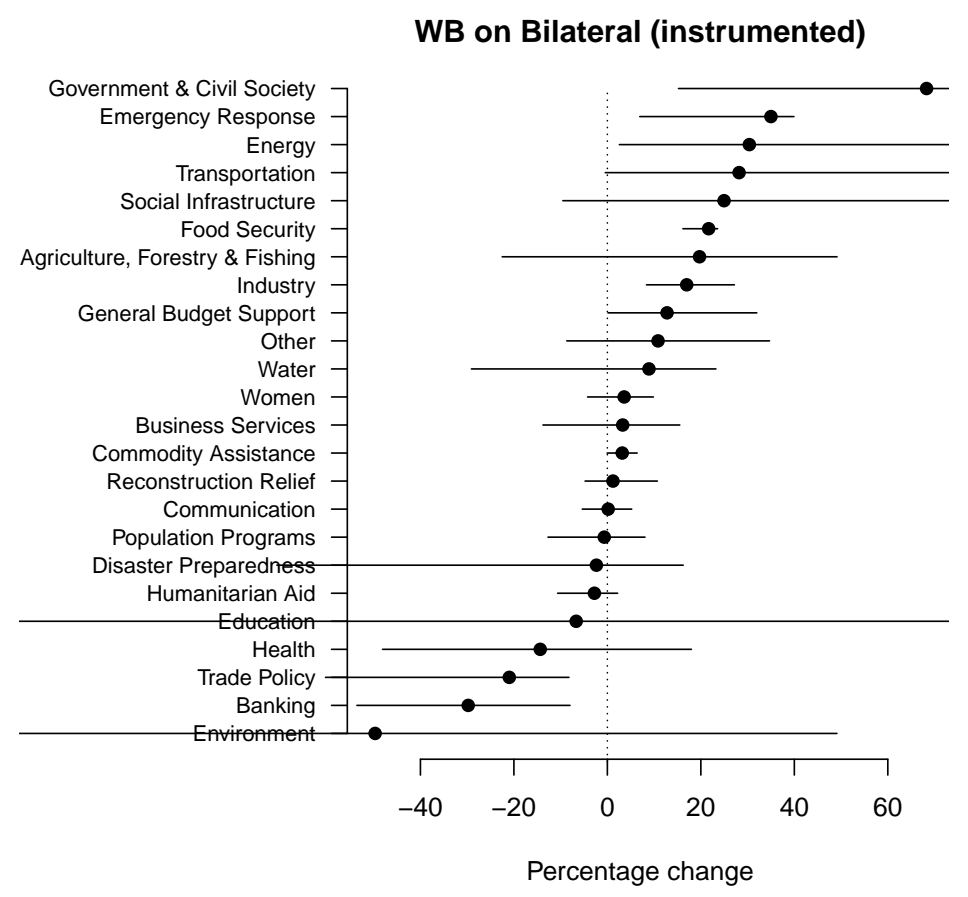

Turning to the instrumental variables analysis (figure 4), the results are indicative, 
but are not estimated with enough precision to decisively disentangle the causal effect of the World Bank on bilateral sector allocation choices. Marginal effects are positive and statistically significant for three sectors, Government \& Civil Society, Food Security, and Industry, with the latter two confirming results from the regression analysis above. Of the remaining 11 sectors from the regression analysis that had a positive and statistically significant relationship, 9 have positive point estimates in the instrumental variables analysis as well, though they are estimated with too much uncertainty. Interestingly, in two sectors we have evidence for the Lead Partner hypothesis (1a). For Trade Policy and Banking, bilateral donors reduce their engagement in reaction to greater World Bank allocations. This chimes with the results from the regression analysis, where both sectors had no statistically significant results.

Taken together, the evidence provides robust support for a complementary relationship between World Bank and bilateral sectoral aid (hypothesis 2) in a large number of sectors. The evidence slightly favors a leading role of the World Bank in inducing bilateral aid allocations to these sectors, though we are careful not to draw strong conclusions in this regard. In addition, the evidence for the World Bank's Lead Partner role in the Trade Policy and Banking sectors highlights the importance of employing a sectoral lens for evaluating the role of World Bank policy leadership. Banking sector aid is aimed at capacity building in the financial system, including government oversight capabilities, central banks, and policy and governance regarding non-formal markets such as in micro credit. Similarly, Trade Policy sector aid aims to strengthen the regulatory framework within which a country trades, ranging from government capacity for policy formulation and enactment, to the support of regional trade agreements and multilateral trade negotiations. The World Bank has been an active driver of aid policies in these two sectors for decades, and possesses technical expertise. It therefore makes sense that bilateral donors would defer to the Bank in these areas. While more research is needed, this insight squares with findings that identify World Bank academic research output as driver of policy conditions in the finance and trade sectors (Cormier and Manger, 2021). 
In the next section, we take another look at these issues by exploring how World Bank leadership affects project proliferation within specific sectors.

\subsection{Project Proliferation}

Given that we found complementarities in allocations for many sectors, what are the implications for observable patterns of project counts? Even with complementarities in sector allocations, there is still room for policy learning if donors can learn from the World Bank how to implement fewer and larger projects. We first turn to the longrun implications of this. As captured by hypothesis 3a, we should expect that when comparing sectors across countries, World Bank engagement should be associated with lower numbers of bilateral projects. Figure 5 presents descriptive evidence that speaks to this relationship.

It shows the empirical distribution of bilateral project counts in sectors in which the World Bank has not been active in 9 consecutive years (dashed line) and compares it to all sectors with at least some World Bank engagement (solid line). For better readability, the square root of counts is shown. The mean number of projects without World Bank is 5.7 and with World Bank engagement 2.6, a statistically significant difference $(t=$ $53.49, p \leq 0.000)$. The densities also show that there are more bilateral projects across the entire range of counts if the World Bank is present in a sector. These patterns suggest that World Bank engagement is associated with significantly higher counts of bilateral projects, contradicting hypothesis $3 \mathrm{a}$, but this comparison does not take into account confounding factors, such as the total amount of aid flowing into a sector.

To control for these factors, we turn to multivariate regression. An appropriate model is negative binomial, since this allows for overdispersion of counts, which is a likely feature of project counts over time (since aid programs are usually multi-year). The dependent variable is the count of bilateral projects per sector, recipient country, and year. The key independent variable is a dummy that marks any sector which did not receive World 
Figure 5: Bilateral Project Count By World Bank Activity

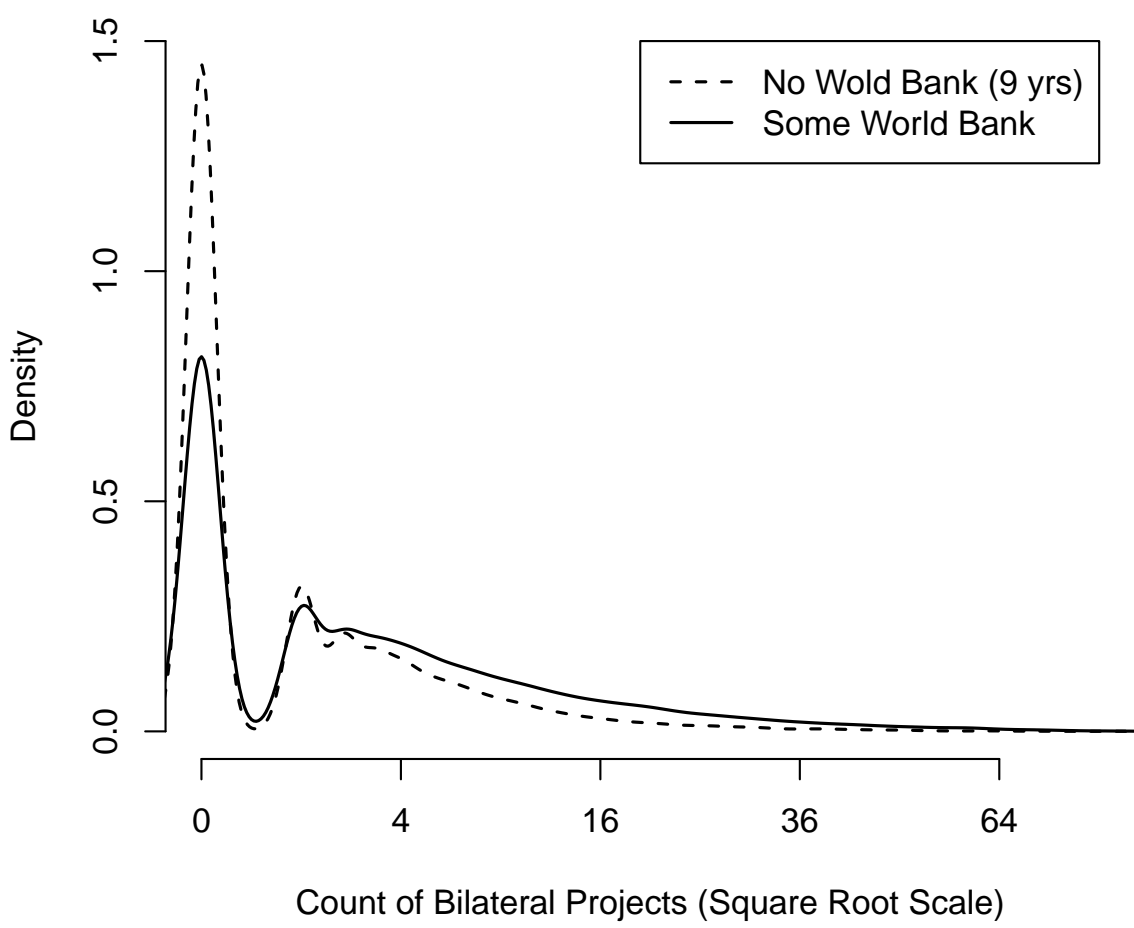

Bank aid for at least 9 years. ${ }^{16}$ We begin with pooling the data across all sectors. The results are reported in table 1 . They confirm the patterns revealed in the descriptive analysis. Model 1 includes only the World Bank dummy and replicates the clear negative relationship between bilateral project counts and the absence of World Bank projects. Model 2 adds controls for the size of flows into each sector, by year and recipient country. The negative relationship persists, and the coefficient for countries without World bank engagement only slightly decreases in size. Model 3 is the most conservative, with sector fixed effects and controls for standard measures of recipient country needs. Again, the negative relationship remains significant at high statistical levels, but the point estimate considerably decreases in size. To get a sense of the substantive importance of this effect, sectors without World Bank programs on average have 2.9 fewer bilateral projects per year, compared to sectors with some World Bank activity (holding other variables at

\footnotetext{
${ }^{16}$ The 9-year period is used to facilitate comparisons with the difference-in-difference results reported below.
} 
their mean).

Table 1: Negative Binomial Regression: Number of Bilateral Projects

\begin{tabular}{|c|c|c|c|}
\hline & $(1)$ & $(2)$ & $(3)$ \\
\hline No WB project in 9 yrs & $\begin{array}{c}-1.654^{* * *} \\
(0.0173)\end{array}$ & $\begin{array}{c}-1.385^{* * *} \\
(0.0175)\end{array}$ & $\begin{array}{c}-0.404^{* * *} \\
(0.0137)\end{array}$ \\
\hline Bilateral aid committed & & $\begin{array}{c}9.21 \mathrm{e}-09^{* * *} \\
(2.29 \mathrm{e}-10)\end{array}$ & $\begin{array}{c}1.42 \mathrm{e}-09^{* * *} \\
(6.02 \mathrm{e}-11)\end{array}$ \\
\hline World Bank aid committed & & $\begin{array}{l}-9.33 \mathrm{e}-12 \\
(9.86 \mathrm{e}-11)\end{array}$ & $\begin{array}{c}1.09 \mathrm{e}-11 \\
(4.63 \mathrm{e}-11)\end{array}$ \\
\hline Population (log) & & & $\begin{array}{c}0.232^{* * *} \\
(0.00286)\end{array}$ \\
\hline GDP per capita & & & $\begin{array}{l}-0.000122^{* * *} \\
(0.00000105)\end{array}$ \\
\hline Constant & $\begin{array}{l}2.608^{* * *} \\
(0.0140)\end{array}$ & $\begin{array}{l}2.141^{* * *} \\
(0.0159)\end{array}$ & $\begin{array}{c}-2.218^{* * *} \\
(0.0609)\end{array}$ \\
\hline lnalpha & $\begin{array}{c}0.869^{* * *} \\
(0.00921)\end{array}$ & $\begin{array}{c}0.748^{* * *} \\
(0.00949)\end{array}$ & $\begin{array}{c}-0.943^{* * *} \\
(0.0146)\end{array}$ \\
\hline Year \& sector fixed effects & no & no & yes \\
\hline Observations & 40045 & 40045 & 38284 \\
\hline
\end{tabular}

The aggregate analysis shows that there is a robust relationship between World Bank engagement and a higher number of bilateral projects in given sector. This contradicts hypothesis $3 \mathrm{a}$ and lends support to hypothesis 4 , which attributes larger project numbers in the presence of World Bank activity to flag-planting and the World Bank's ability to impose greater selectivity on recipient countries. To further probe this relationship, we disaggregate the analysis and run sector-specific regressions (results reported in table B3 in the Online Supplementary Appendix B). This allows us to include sector-specific control variables. While not all sectors show significant associations between World Bank engagement and the number of bilateral projects - likely the result of substantively lower statistical power in sector-by-sector analysis - we obtain negatively significant associa- 
tions in 15 sectors. In no case is there a positively significant association. Note that the Finance and Trade Policy sectors for which we found substitution patterns in the sector allocation analysis also show negative and statistically significant associations. A remaining challenge to inference, however, is that without identification strategy it is not possible to causally attribute bilateral donor behavior to World Bank actions. In order to remedy this, in the next step we turn to a difference-in-difference (diff-in-diff) design.

From a diff-in-diff perspective and in the language of causal analysis, World Bank engagement is a treatment, and we need to compare cases that experienced this treatment with a control group that did not. To apply this idea to data in sector-recipient countryyear format, we rely on temporal ordering. World Bank engagement should make the most difference in instances where the World Bank was initially not active and then starts a new program. To operationalize this, we define treatment cases as those which did not have any World Bank program in years $t_{-4}$ to $t_{-1}$, but receive World Bank aid in $t_{0}$. Cases can experience several instances of treatment, but the next consecutive treatment can start at the earliest in $t_{5}$. Thus, each case of treatment covers a time period of nine years from $t_{-4}$ to $t_{4}$. The choice of 4 years as minimum period between treatments reflects the typical length of programs of around 3 to 4 years.

As control cases, there is a wide choice of possible characteristics. We use two. First, we treat every observation as a control case if it does not adhere to the treatment scheme. This will result in a mixture of cases that involve relatively high and relatively low World Bank engagement. Second, we identify sectors which did not receive any World Bank aid in 9 consecutive years. This matches the length of treatment periods, and constitutes a stricter concept of control.

The approach pursued here misses one aspect of typical diff-in-diff approaches. Treatment and control cases do not necessarily start at synchronous times. In addition, for reasons of preserving statistical power, the analysis is not performed sector-by-sector, but data is pooled across sectors (though we report sector-specific results in Online Supplementary Appendix B and provide an overview below). Both features risk a violation of 
the assumption that treated and untreated cases follow a similar trend in the absence of the treatment. To address this, we include year fixed effects to account for secular time trends, and sector fixed effects to capture differences in allocation behavior across different sectors. Other sources of heterogeneity necessarily will go unaddressed because of insufficient degrees of freedom, such as variation specific to joint country-sector properties.

Table 2: Diff-in-Diff: Number of Bilateral Projects

\begin{tabular}{|c|c|c|c|c|}
\hline Comparison group & $\begin{array}{c}(1) \\
\text { all cases }\end{array}$ & $\begin{array}{c}(2) \\
\text { all cases }\end{array}$ & $\begin{array}{c}(3) \\
\text { all cases }\end{array}$ & $\begin{array}{c}(4) \\
\text { no WB projects }\end{array}$ \\
\hline Treatment group & $\begin{array}{l}0.911^{* * *} \\
(0.0262)\end{array}$ & $\begin{array}{l}0.914^{* * *} \\
(0.0238)\end{array}$ & $\begin{array}{l}0.107^{* * *} \\
(0.0127)\end{array}$ & $\begin{array}{l}0.190^{* * *} \\
(0.0184)\end{array}$ \\
\hline Treatment years $t_{0}-t_{4}$ & $\begin{array}{l}0.244^{* * *} \\
(0.0353)\end{array}$ & $\begin{array}{l}0.0641^{*} \\
(0.0321)\end{array}$ & $\begin{array}{c}0.0750^{* * *} \\
(0.0162)\end{array}$ & $\begin{array}{c}0.0899^{* * *} \\
(0.0178)\end{array}$ \\
\hline Bilateral aid committed & & $\begin{array}{c}1.82 \mathrm{e}-08^{* * *} \\
(2.68 \mathrm{e}-10)\end{array}$ & $\begin{array}{c}2.04 \mathrm{e}-09^{* * *} \\
(5.98 \mathrm{e}-11)\end{array}$ & $\begin{array}{c}2.83 \mathrm{e}-09^{* * *} \\
(1.06 \mathrm{e}-10)\end{array}$ \\
\hline World Bank aid committed & & $\begin{array}{c}1.90 \mathrm{e}-09^{* * *} \\
(1.38 \mathrm{e}-10)\end{array}$ & $\begin{array}{l}9.37 \mathrm{e}-11^{*} \\
(4.46 \mathrm{e}-11)\end{array}$ & $\begin{array}{l}-4.84 \mathrm{e}-13 \\
(8.29 \mathrm{e}-11)\end{array}$ \\
\hline Population (log) & & & $\begin{array}{c}0.263^{* * *} \\
(0.00218)\end{array}$ & $\begin{array}{c}0.240^{* * *} \\
(0.00317)\end{array}$ \\
\hline GDP per capita & & & $\begin{array}{c}-0.000113^{* * *} \\
(0.000000732)\end{array}$ & $\begin{array}{l}-0.000129^{* * *} \\
(0.00000120)\end{array}$ \\
\hline Constant & $\begin{array}{l}1.292^{* * *} \\
(0.00728)\end{array}$ & $\begin{array}{c}0.803^{* * *} \\
(0.00777)\end{array}$ & $\begin{array}{c}-3.028^{* * *} \\
(0.0437)\end{array}$ & $\begin{array}{c}-2.741^{* * *} \\
(0.0618)\end{array}$ \\
\hline lnalpha & $\begin{array}{c}1.156^{* * *} \\
(0.00653)\end{array}$ & $\begin{array}{c}0.941^{* * *} \\
(0.00688)\end{array}$ & $\begin{array}{l}-0.813^{* * *} \\
(0.0112)\end{array}$ & $\begin{array}{l}-0.817^{* * *} \\
(0.0161)\end{array}$ \\
\hline Year \& sector fixed effects & no & no & yes & yes \\
\hline Observations & 75600 & 75600 & 71750 & 34816 \\
\hline
\end{tabular}

Table 2 shows the results of the analysis. Starting with the control group that encompasses all non-treatment cases, model 1 includes only the dummy for the treatment group, and the dummy marking the year when the World Bank program was introduced 
$\left(t_{0}\right)$ and covering the following 4 years $\left(t_{1}\right.$ to $\left.t_{4}\right)$. We can see that there was a systematically higher bilateral project count during the treatment years. However, just being in the treatment group had a substantively greater effect as well, even before the first World Bank program was introduced. This indicates a violation of the parallel trend assumption which requires that differences between treatment and control groups arise only from the treatment. Adding controls for bilateral and World Bank aid volumes (model 2), recipient country needs, and year and sector fixed effects (model 3) reduce this effect, but cannot fully erase it. A similar pattern emerges for using as control group sectors that did not have any World Bank engagement over 9 years (model 4).

In table B3 in Online Supplementary Appendix B, we extend model 4 further by adding sector-specific control variables and estimating equations for each sector individually. We find a significantly positive association between World Bank treatment years and the number of bilateral projects, but in only four sectors, namely Governance, Other Social Services, Communications, and Finance. For all other sectors, coefficients remain statistically insignificant, which may partly be due to power issues. Note that for the Finance sector this finding is the opposite of what we observed for sector shares, i.e. World Bank activity is associated with more bilateral projects and not fewer. Overall, our conclusion holds that there is some evidence of a bilateral crowding-in effect in terms of project numbers when the World Bank enters a sector anew.

Returning to model 4, to illustrate how the treatment group differs from the control year by year, figure 6 breaks down the effect of being in the control group over time. This is done by re-estimating model 4 with separate year-intercepts for observations that are in the treatment group. The graph shows the difference in the number of expected bilateral projects between the treatment and control groups (bullets) in a given year and 95 percent confidence bands (whiskers). ${ }^{17}$ The results demonstrate that there is a statistically identifiable increase in bilateral project counts up to two years prior to the World Bank entering a sector, followed by a marked and sustained jump in project counts

\footnotetext{
${ }^{17}$ Holding all other variables at their mean, and setting all fixed effect dummies to zero.
} 
Figure 6: Diff-in-Diff: Treatment group by year

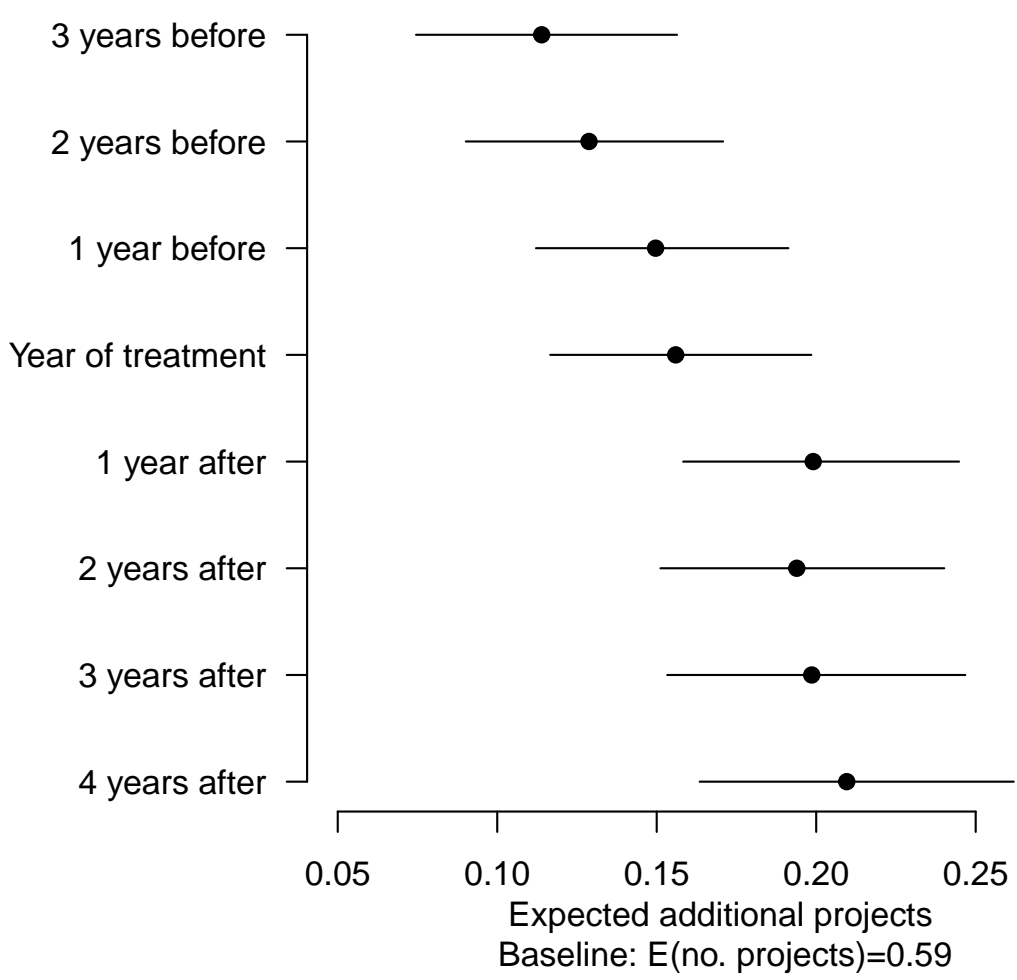

in the years after the World Bank enters.

The increase in project counts prior to the treatment year also illustrates that the diff-in-diff design does not provide us with enough leverage to distinguish a clear causal pattern. While it is possible that bilateral project counts increase in anticipation of World Bank activity, the World Bank could also be reacting to an observed proliferation of projects. In addition, we can't rule out that country-sector specific exogenous shocks account for the movement of both variables. However, figure 6 also reveals a robust empirical pattern of persistent higher bilateral project counts in the aftermath of World Bank engagement. Importantly, there is a jump in the year after the World Bank enters a sector $\left(t_{1}\right)$. This jump is statistically significant at the 0.1 level $(z \leq 0.073)$ relative to the prior year $\left(t_{0}\right)$, with differences to previous years being highly statistically significant. ${ }^{18}$ The temporal ordering of this jump in project numbers confirms to the expectation that bilateral aid providers react to observed World Bank actions.

\footnotetext{
${ }^{18} t_{1}-t_{-1}=0, p \leq 0.030 ; t_{1}-t_{-2}=0, p \leq 0.0017 ; t_{1}-t_{-3}=0, p \leq 0.0001$.
} 
This change in behavior is substantively important. In the year after the Word Bank enters, a sector receives on average 0.20 more projects per year than sectors in the control group. To put this into perspective, the average number of projects per year in the control group is 0.59 . Treated cases therefore have a 33.9 percent higher count of bilateral projects than control cases. Even when taking into account that bilateral project numbers start increasing prior to World Bank activity, this effect is large. 3 years before the World Bank enters a sector, the treatment group has only 0.11 bilateral projects more than the control group, amounting to a 18.6 percent difference. Thus moving from $t_{-3}$ to $t_{1}$ represents a jump of 15.3 percentage points in how much project counts differ between treatment and control group.

Overall, while the analysis did not provide definite answers regarding causal direction, the revealed patterns underline the findings from the cross-sectional analysis in table 1. World Bank activity in a sector is associated with an increase in the number of bilateral projects. In addition, there is a marked jump in bilateral project proliferation after the World Bank enters a sector. Together these observations are enough to safely refute hypothesis 3b. There is no evidence that bilateral donors learn from World Bank best practices and move to fewer and larger projects when engaging in the same sector as the World Bank. On the contrary, there is a clear complementary relationship in line with hypothesis 4, which associates World Bank activity with increased proliferation of bilateral aid projects. This pattern also holds for the Finance and Trade sectors, for which we found a substitution relationship in the analysis of sector aid allocations.

\section{Conclusion}

This paper started with the observation that the academic debate on aid proliferation and donor coordination is overly focused on aggregate aid patterns, but fails to focus on policy mechanisms. To make headway in this direction, we proposed that the World Bank has the potential to play an important role as Lead Partner and Balancer in 
promoting greater specialization of allocations across aid sectors, as well as promoter of Best Practices in delivering aid while controlling project numbers. However, we could find no evidence of Balancer behavior, and the evidence for a Lead Partner role is limited to the Finance and Trade sectors. In contrast, with high certainty World Bank and bilateral donors allocate aid in complementary fashion across a wide range of sectors. Instead of promoting cross-sector specialization, this contributes to concentration of projects into popular sectors and leaves other sectors underaided. On the question whether the World Bank promulgates best practices that help reduce bilateral project numbers, the emerging picture is equally negative. Bilateral project numbers are higher - not lower - in sectors in which the World Bank is also present. In addition, there is some evidence that this increase in fact occurs in reaction to World Bank activity.

With the post-war liberal world order under increasing strain, and with the arrival of important new actors on the aid scene, there is a growing need to better understand how international institutions can shape bilateral behavior. The World Bank, as largest multilateral actor in development and important repository of technical knowledge, should be well situated to promote best policy practices. This can help mend a fraying policy consensus among western governments. It also has the potential to moderate the growing competition between traditional and newly ascendant aid providers. Academic research and policy makers alike need to strengthen their focus on policy mechanisms and strategies that can help undergird an outcome oriented development agenda. In this context, future research might also address the potential role of trust funds for donor coordination. From an analytical perspective, future research should analyze why the World Bank apparently fails to effectively constrain bilateral aid project proliferation at the sector level. This would help identify possible policy levers for reducing fragmentation. 


\section{References}

AidData. 2017. AidDataCore_ResearchRelease_Level1_v3.1 Research Releases dataset. Williamsburg, VA: AidData. Accessed on 1/1/17. http://aiddata.org/datasets.

Annen, Kurt and Stephen Knack. 2018. "On the delegation of aid implementation to multilateral agencies." Journal of Development Economics 133:295-305.

Bartik, Timothy J. 1991. Who benefits from state and local economic development policies? Kalamazoo, MI: WE Upjohn Institute for Employment Research.

Bauer, Michael W and Jörn Ege. 2016. "Bureaucratic autonomy of international organizations' secretariats." Journal of European Public Policy 23(7):1019-1037.

Clark, Richard and Lindsay R Dolan. 2021. "Pleasing the principal: US influence in World Bank policymaking." American Journal of Political Science 65(1):36-51.

Cormier, Ben and Mark S Manger. 2021. "Power, ideas, and World Bank conditionality." The Review of International Organizations . DOI: https://doi.org/10.1007/ s11558-021-09427-z.

Courtright, Christina. 2004. "Which lessons are learned? Best practices and World Bank rural telecommunications policy." The Information Society 20(5):345-356.

Davies, Ronald B and Stephan Klasen. 2019. "Darlings and orphans: Interactions across donors in international aid." The Scandinavian Journal of Economics 121(1):243-277.

Easterly, William. 2001. The Elusive Quest for Growth: Economists' Adventures and Misadventures in the Tropics. Cambridge and London: MIT Press.

Easterly, William. 2007. "Are Aid Agencies Improving?" Economic Policy 22(52):633678. 
Efron, Bradley and Robert Tibshirani. 1986. "Bootstrap methods for standard errors, confidence intervals, and other measures of statistical accuracy." Statistical science $1(1): 54-75$.

Eichenauer, Vera Z and Bernhard Reinsberg. 2017. "What determines earmarked funding to international development organizations? Evidence from the new multi-bi aid data." The Review of International Organizations 12(2):171-197.

Fritz, Verena, Kai Kaiser and Brian Levy. 2009. "Problem-driven governance and political economy analysis: good practice framework.".

Fuchs, Andreas, Peter Nunnenkamp and Hannes Öhler. 2015. "Why donors of foreign aid do not coordinate: The role of competition for export markets and political support." The World Economy 38(2):255-285.

Gehring, Kai, Katharina Michaelowa, Axel Dreher and Franziska Spörri. 2017. "Aid Fragmentation and Effectiveness: What Do We Really Know?" World Development 99:320-334.

Heldt, Eugénia C and Henning Schmidtke. 2019. "Explaining coherence in international regime complexes: How the World Bank shapes the field of multilateral development finance." Review of International Political Economy 26(6):1160-1186.

Hijazi, Rafiq H and Robert W Jernigan. 2009. "Modelling compositional data using Dirichlet regression models." Journal of Applied Probability 6 Statistics 4(1):77-91.

Humphrey, Chris and Katharina Michaelowa. 2019. "China in Africa: Competition for traditional development finance institutions?" World Development 120:15 - 28.

URL: http://www.sciencedirect.com/science/article/pii/S0305750X19300725

International Development Association. 2007. "IDA's Role in Enhancing CountryLevel Effectiveness: Strengthening Harmonization and Alignment." accessed online on 
5 April 2019 at http://siteresources.worldbank.org/IDA/Resources/Seminar\% 20PDFs/73449-1172525976405/3492866-1175095887430/HandA .pdf.

Johnson, Tana and Johannes Urpelainen. 2014. "International bureaucrats and the formation of intergovernmental organizations: Institutional design discretion sweetens the pot." International Organization 68(1):177-209.

Kilby, Christopher. 2011. "What determines the size of aid projects?" World Development 39(11):1981-1994.

Kimura, Hidemi, Yuko Mori and Yasuyuki Sawada. 2012. "Aid Proliferation and Economic Growth: A Cross-Country Analysis." World Development 40(1):1-10.

Kindleberger, Charles. 1973. The World in Depression, 1929-1939. University of California Press.

Knack, Stephen and Aminur Rahman. 2007. "Donor fragmentation and bureaucratic quality in aid recipients." Journal of Development Economics 83(1):176-197.

Maier, Marco J. 2014. "DirichletReg: Dirichlet regression for compositional data in R." Vienna University of Economics and Business Research Report Series 125.

Malik, Rabia and Randall W Stone. 2018. "Corporate influence in World Bank lending." The Journal of Politics 80(1):103-118.

Mascarenhas, Raechelle and Todd Sandler. 2006. "Do Donors Cooperatively Fund Foreign Aid?" Review of International Organizations 1:337-357.

Milner, Helen V. 2006. Why multilateralism? Foreign aid and domestic principalagent problems. In Delegation and agency in international organizations, ed. Darren G. Hawkins, David A. Lake, Daniel L. Nielson and Michael J. Tierney. Cambridge: Cambridge University Press pp. 107-139. 
Nunnenkamp, Peter, Albena Sotirova and Rainer Thiele. 2015. "Do Aid Donors Specialize and Coordinate within Recipient Countries? The Case of Malawi." Kiel Working Papers 1991. accessed online on $8 / 10 / 16$ at https://www.ifw-members.ifw-kiel.de/publications/ do-aid-donors-specialize-and-coordinate-within-recipient-countries-the-case-of-mal kwp_1991.pdf.

Nunnenkamp, Peter, Hannes Öhler and Rainer Thiele. 2013. "Donor coordination and specialization: did the Paris Declaration make a difference?" Review of World Economics 149(3):537-563.

OECD. 2008. The Paris Declaration on Aid Effectiveness and the Accra Agenda for Action. Paris: OECD. http://www.oecd.org/dac/effectiveness/34428351.pdf, accessed on 4-30-2018.

Ostrom, Elinor, Larry Schroeder and Susan Wynne. 1993. Institutional Incentives and Sustainable Development: Infrastructure Policies in Perspective. Boulder, CO: Westview Press.

Reinsberg, Bernhard, Katharina Michaelowa and Stephen Knack. 2017. "Which Donors, Which Funds? Bilateral Donors' Choice of Multilateral Funds at the World Bank." International Organization 71(4):767?802.

Rodrik, Dani. 1995. "Why is there multilateral lending?" NBER Working Paper Series 5160.

Rodrik, Dani. 2008. "Second-best institutions." American economic review 98(2):100104.

Schneider, Christina J and Jennifer L Tobin. 2013. "Interest coalitions and multilateral aid allocation in the European Union." International Studies Quarterly 57(1):103-114. 
Snidal, Duncan. 1985. "The limits of hegemonic stability theory." International organization 39(4):579-614.

Steinwand, Martin C. 2015. "Compete or Coordinate? Aid Fragmentation and Lead Donorship." International Organization 69(2):443-472.

Stone, Randall W. 2011. Controlling Institutions: International Organizations and the Global Economy. Cambridge: Cambridge University Press.

The World Bank. 1998. World Bank Development Report: Knowledge for Development. New York, NY: Oxford University Press for the World Bank.

The World Bank. 2005. "Global Monitoring Report.". accessed online on 5 April 2019 at https://www.imf .org/external/pubs/ft/gmr/2005/eng/pdf/gmr.pdf.

The World Bank. 2014. "World Bank Group Directive: Country Engagement." accessed online on 5 April 2019 at https://policies.worldbank.org/sites/ppf3/ PPFDocuments/090224b082538b9a.pdf.

Tierney, Michael J, Daniel L Nielson, Darren G Hawkins, J Timmons Roberts, Michael G Findley, Ryan M Powers, Bradley Parks, Sven E Wilson and Robert L Hicks. 2011. "More dollars than sense: Refining our knowledge of development finance using AidData." World Development 39(11):1891-1906.

Vadlamannati, Krishna Chaitanya, Yuanxin Li, Samuel Brazys and Alexander Dukalskis. 2019. "Building Bridges or Breaking Bonds? The Belt and Road Initiative and Foreign Aid Competition." AidData Working Paper 72. Accessed on June 14, 2019 at http://docs.aiddata.org/ad4/pdfs/WPS72_Building_Bridges_or_Breaking_ Bonds--The_Belt_and_Road_Initiative_and_Foreign_Aid_Competition.pdf.

Weaver, Catherine. 2008. Hypocrisy trap: The World Bank and the poverty of reform. Princeton University Press. 
Winters, Matthew S. 2012. "The Obstacles to Foreign Aid Harmonization: Lessons from Decentralization Support in Indonesia." Studies in Comparative International Development 47(3):1-26.

World Bank Operations Evaluation Department. 2000. "The Drive to Partnership: Aid Coordination and the World Bank." Précis 201. accessed online on 5 April 2019 at http: //documents . worldbank .org/curated/en/695441468778194611/pdf / multiOpage.pdf.

Yanguas, Pablo and David Hulme. 2015. "Barriers to political analysis in aid bureaucracies: From principle to practice in DFID and the World Bank." World Development 74:209-219.

Zeitz, Alexandra O. 2021. "Emulate or differentiate?" The Review of International Organizations 16(2):265-292. 